\title{
ANALISIS KESALAHAN BERBAHASA BIDANG SINTAKSIS DALAM TEKS BIOGRAFI SISWA KELAS X SMA NEGERI 7 PADANG
}

\author{
Afnita $^{1}$, Eriska Kurnia ${ }^{2}$, Herfina Assadiyah ${ }^{3}$ \\ Universitas Negeri Padang \\ athailah.afif@yahoo.co.id
}

\begin{abstract}
ABSTRAK
Penelitian ini bertujuan untuk: (1) mendeskripsikan dan menjelaskan kesalahan berbahasa pada bidang sintaksis dalam menulis teks biografi siswa kelas X SMA Negeri 7 Padang dan (2) mendeskripsikan dan menjelaskan analisis bentuk kesalahan berbahasa pada bidang sintaksis dalam menulis teks biografi siswa kelas X SMA Negeri 7 Padang. Jenis penelitian ini adalah penelitian kualitatif deskriptif. Sumber data dalam penelitian ini adalah teks biografi siswa kelas X SMA Negeri 7 Padang. Teknik pengumpulan data penelitian adalah observasi, wawancara, dan studi dokumen. Hasil penelitian mengenai analisis kesalahan berbahasa pada bidang sintaksis dalam menulis teks biografi siswa kelas X SMA Negeri 7 Padang dapat dibagi menjadi tiga aspek (1) kalimat ambigu, (2) diksi yang tidak tepat dalam membentuk kalimat, dan (3) logika kalimat.
\end{abstract}

Kata kunci: teks biografi, sintaksis, kesalahan berbahasa

\section{A. PENDAHULUAN}

Pelajaran Bahasa Indonesia dalam pendidikan dapat membantu siswa untuk mengerti dan memahami tentang kaidah bahasa, penggunaan bahasa, dan tuturan secara langsung maupun tidak langsung, saat berkomunikasi antarmanusia pada kehidupan sehari-hari. Mata pelajaran Bahasa Indonesia tidak hanya mengajarkan seluk beluk tentang bahasa pada umumnya, tetapi juga tentang tataran fonologi, morfologi, sintaksis, dan semantik.

Kurikulum 2013 telah menggunakan pendekatan berbasis teks. Pembelajaran bahasa Indonesia berbasis teks dilaksanakan dengan menerapkan prinsip bahwa bahasa hendaknya dipandang sebagai teks, bukan semata-mata kumpulan kata atau kaidah- kaidah kebahasaan, penggunaan bahasa merupakan proses pemilihan bentuk kebahasaan untuk mengungkapkan makna, bahasa bersifat fungsional, yaitu penggunaan bahasa tidak pernah dapat dilepaskan dari konteks, bahasa merupakan sarana pembentukan kemampuan berpikir manusia (Nurtia, 2016).

Menurut Septiana (dalam Jurnal Basastra 2015) bahasa digunakan untuk berhubungan dengan masyarakat luas. Begitu pula pada pembelajaran di sekolah. Pembelajaran yang terjadi antara siswa, guru, dan lingkungan memerlukan bahasa sebagai alat komunikasi, berinteraksi, dan berhubungan.

Bahasa kedua (bahasa Indonesia) diperoleh anak setelah mereka memperoleh 


\section{DEIKSIS - JURNAL PENDIDIKAN BAHASA DAN SASTRA INDONESIA}

bahasa pertama (bahasa daerah). Suyitno (dalam Setiawan, 2016) beranggapan bahwa pemeroleh bahasa kedua dipengaruhi secara kuat oleh bahasa pertama. Mackey (dalam Setiawan, 2016) juga beranggapan bahwa anak akan menggunakan pola bahasa pertama yang mereka kuasai secara mendalam pada saat berbahasa kedua. Anak secara tidak sadar terpengaruh bahasa pertama. Hal ini merupakan penyebab utama kesalahan dalam bahasa kedua. Bentuk pengaruh tersebut misalnya terjadinya kesalahan berbahasa, yaitu penyimpangan atau kelanggaran bahasa yang tidak sesuai dengan kaidah bahasa Indonesia baku, baik kesalahan pemilihan kata, struktur, maupun gramatikal. Kesalahan-kesalahan ini wajar dialami oleh setiap penutur yang berdwibahasa.

Menulis teks biografi merupakan teori pokok yang harus diajarkan kepada siswa Sekolah Menengah Atas (SMA). Materi tersebut sesuai dengan Kurikulum 2013, pada Kompetensi Inti (KI) ke-4 yaitu mencoba, mengolah, dan menyaji dalam ranah konkret (menulis, membaca, menghitung, menggambar, dan mengarang) sesuai dengan yang dipelajari di sekolah dan sumber lain yang sama dalam sudut pandang dan teori. Selanjutnya dijabarkan pada Kompetensi Dasar (KD) ke-4.15 yaitu menyusun teks biografi tokoh sesuai dengan karakteristik teks yang akan dibuat secara lisan maupun tulisan.

Kurangnya kemampuan siswa kelas X SMA Negeri 7 Padang dalam menulis kalimat efektif menyebabkan teks yang ditulis memiliki kesalahan. Permasalahan tersebut sependapat dengan salah seorang guru bahasa Indonesia di SMA Negeri 7 Padang. Berdasarkan wawancara yang dilakukan tanggal 29 Maret 2018, beliau mengemukakan bahwa kebanyakan siswa belum terampil menulis. Pertama, siswa belum terbiasa menulis teks. Kedua, siswa kesulitan dalam membuat kalimat dan kurang mampu memilih diksi. Ketiga, siswa kesulitan dalam menuangkan ide, atau gagasannya menjadi sebuah kalimat. Keempat, kalimat yang ditulis siswa dalam memproduksi teks cenderung tidak efektif.

Berdasarkan kesalahan dalam teks siswa tersebut, ditemukan masalah yaitu kesalahan berbahasa dalam bidang sintaksis. Kesalahan tersebut adalah penggunaan kalimat yang ambigu, kesalahan diksi yang tidak tepat dalam membentuk kalimat, dan kesalahan logika kalimat yang terdapat dalam teks biografi siswa kelas X SMA Negeri 7 Padang.

Dalam dunia pendidikan menulis sangat penting. Menulis membantu seseorang berpikir lebih mudah. Menulis adalah suatu alat yang sangat ampuh dalam belajar dengan sendirinya memainkan peran yang sangat penting dalam dunia pendidikan. Untuk memperkuat mengenai tujuan menulis siswa SMA Negeri 7 Padang, akan dipaparkan mengenai pengertian menulis. Menulis adalah kegiatan menyampai sesuatu menggunakan bahasa melalui tulisan dengan maksud dan pertimbangan tertentu mencapai sesuatu yang dikehendaki (Rahardi dalam Kusumaningsih, 2013).

Berdasarkan latar belakang tersebut peneliti melakukan penelitian mengenai analisis kesalahan berbahasa pada bidang 


\section{DEIKSIS - JURNAL PENDIDIKAN BAHASA DAN SASTRA INDONESIA}

sintaksis saat siswa menulis karangan yang dikembangkan. Hal ini akan terlihat saat siswa diberi tugas untuk menulis sebuah karangan berdasarkan pemikiran apakah kalimat yang ditulis sudah memenuhi kaidah kebahasaan yang baik dan benar. Peneliti juga mengharapkan supaya dapat menjadi rencana selanjutnya untuk mengembangkan pelajaran bahasa Indonesia yang baik dan benar.

Kata sintaksis berasal dari Yunani, yaitu sun yang berarti "dengan" dan tattein yang berarti "menempatkan". Jadi, secara etimologi sintaksis berarti mendapatkan bersama-sama kata-kata menjadi kelompok kata atau kalimat. Suhardi (dalam Setiawan, 2016) mengatakn bahwa sintaksis adalah cabang ilmu bahasa yang sudah sangat tua, menyelidiki struktur kalimat dan kaidah penyusunan kalimat. erdasarkan pendapat tersebut, disimpulkan bahwa sintaksis adalah ilmu bahasa yang menyelidiki struktur kalimat dan penyusunan kalmiat. Sementara itu, Ramlan (dalam Setiawan, 2016) menyatakan bahwa sintaksis merupakan ilmu yang mempelajari hubungan antara kata atau frase atau klausa atau kalimat yang satu dengan yang lain, atau mempelajari seluk beluk frase, klausa, kalimat, dan wacana.

Alwi, dkk (2013) menyatakan bahwa kalimat adalah satuan terkecil, dalam wujud wacana lisan atau tulisan, yang mengungkapkan pikiran yang utuh. Menurut Chaer (2009), kalimat adalah satuan sintaksis yang disusun dari konstituen dasar yang biasanya berupa klausa, dilengkapi dengan konjungsi bila diperlukan serta disertai dengan intonasi final. Menurut Atmazaki (2006), kalimat adalah satuan bahasa yang lebih besar dari pada frase yang unsur-unsurnya mempunyai fungsi sebagi subjek, predikat, objek, pelengkap atau keterangan.

Menurut Santoso (dalam Jurnal Humaniora, 2007), diksi adalah pilihan kata yang tepat dan selaras untuk mengungkapkan suatu gagasan sehingga gagasan itu dapat diterima oleh pendengar atau pembaca dengan tepat. Pemilihan katakata yang layak atau pantas penting sekali dalam semua bentuk komunikasi, terutama dalam bahasa tulis yang harus membawakan ide atau gagasan dan sikap tanpa peragaan, ekspresi, intonasi, atau isyarat berupa gerakan tubuh.

Penelitian ini bertujuan: mendeskripsikan dan menjelaskan jenis bentuk kesalahan berbahasa pada bidang sintaksis dalam teks biografi siswa kelas $\mathrm{X}$ SMA Negeri 7 Padang, dan (2) mendeskripsikan dan menjelaskan penyebab terjadinya berbentuk kesalahan berbahasa pada bidang sintaksis dalam teks biografi siswa kelas X SMA Negeri 7 Padang.

Penelitian ini sebelumnya pernah dilakukan oleh Syafni Nurtia yang berjudul "Kesalahan Kalimat dalam Teks Eksposisi Siswa Kelas VII SMP Negeri 12 Padang". Penelitian ini menyimpulkan empat kesalahan kalimat dalam teks eksposisi siswa kelas VII SMP Negeri 12 Padang, yaitu (1) kesalahan kalimat pada aspek struktur fungsi sintaksis berupa penggunaan predikat tidak tepat, (2) kesalahan kalimat pada aspek kekurangan unsur kalimat, (3) kesalahan kalimat pada aspek kelebihan unsur kalimat dan (4) kesalahan kalimat pada aspek diksi. Selain itu, penelitin ini 


\section{DEIKSIS - JURNAL PENDIDIKAN BAHASA DAN SASTRA INDONESIA}

juga pernah dilakukan oleh Septiana (2015) yang berjudul "Analisis Kesalahan Struktur Teks dan Pemakaian Bahasa Indonesia pada Teks Biografi Karya Siswa SMP”. Penelitian ini menyimpulkan tiga kesalahan struktur teks, yaitu (1) kesalahan urutan struktur teks, (2) kesalahan pemakaian bahasa Indonesia seperti ejaan, diksi, dan kalimat, (3) kesalahan struktur teks dan pemakaian bahasa Indonesia oleh beberapa faktor.

\section{B. METODE PENELITIAN}

Jenis penelitian ini adalah kualitatif deskriptif. Adapun fakta-fakta yang akan dideskripsikan adalah bentuk kesalahan berbahasa bidang sintaksis dalam menulis teks biografi siswa Kelas X SMA Negeri 7 Padang. Penelitian ini dilakukan di SMA Negeri 7 Padang. Sumber data adalah subjek dari mana asal penelitian diperoleh. Apabila peneliti misalnya menggunakan kuesioner atau wawancara dalam pengumpulan datanya, sumber datanya disebut responden, yaitu orang yang merespon atau menjawab pertanyaan baik yang tertulis maupun lisan (Suwarjeni, 2014).

Data dalam penelitian ini berupa bentuk kesalahan berbahasa pada bidang sintaksis dalam menulis teks biografi siswa kelas X SMA Negeri 7 Padang. Sumber data dalam penelitian ini adalah teks biografi karangan siswa kelas X SMA Negeri 7 Padang. Narasumber dalam penelitian ini yaitu siswa kelas X SMA Negeri 7 Padang.

Instrumen penelitian ini adalah peneliti sendiri. Pemanfaatan manusia atau peneliti sebagai instrumen penelitian dilandasi oleh keyakinan bahwa hanya manusia yang mampu menilai makna dari suatu peristiwa atau berbagai interaksi sosial (Moleong, 2012).

Teknik pengumpulan data yang digunakan dalam penelitian ini adalah observasi, wawancara, dan studi dokumen. Peneliti hadir di sekolah untuk melakukan observasi mengenai kondisi lingkungan sekolah dan proses pembelajaran siswa kelas $\mathrm{X}$ SMA Negeri 7 Padang mengenai pelajaran bahasa Indonesia di kelas. Setelah melakukan observasi, peneliti melakukan wawancara dengan guru Mata Pelajaran Bahasa Indonesia kelas X SMA Negeri 7 Padang. Setelah peneliti melakukan tahap observasi dan wawancara akan dilanjutkan dengan studi dokumen.

Data dikumpulkan dengan cara meminjam tugas teks biografi siswa kepada guru Mata Pelajaran Bahasa Indonesia kelas X SMA Negeri 7 Padang. Peneliti hanya membahas dan meneliti 30 teks biografi yang ditulis oleh siswa kelas X SMA Negeri 7 Padang. Teks biografi tersebut dianalisis dengan cara membaca dan memahami kalimat yang terkandung di dalamnya. Hal ini bertujuan untuk memperoleh pemahaman yang jelas tentang isi teks yang akan diteliti.

\section{PEMBAHASAN HASIL PENELITIAN}

Berdasarkan analisis yang telah dilakukan terdapat bentuk kesalahan berbahasa pada bidang sintaksis dalam menulis teks biografi siswa kelas X SMA Negeri 7 Padang. Analisis kesalahan tersebut dijelaskan sebagai berikut. 


\section{DEIKSIS - JURNAL PENDIDIKAN BAHASA DAN SASTRA INDONESIA}

\section{Kalimat Ambigu}

Kalimat ambigu adalah kalimat yang bermakna lebih dari satu atau bermakna ganda sehingga kadang-kadang menimbulkan keraguan atau ketidakjelasan.

Dalam klasifikasi kalimat ambigu terdapat bentuk kesalahan yang dipaparkan sebagai berikut.

1) Kami sekeluarga tidak bertahan lama di Pekanbaru, karena ayahku lagi-lagi ditugaskan kerja ke Jambi.

Kalimat (1) merupakan kalimat ambigu karena adanya penanda jamak dalam penggunaan kata. Penggunaan kata cukup satu penanda untuk menjelaskan, misalnya kata lagi-lagi cukup ditulis satu kali saja atau dihilangkan agar kalimat menjadi efektif. Bentuk benar dari kalimat (1) tersebut adalah kami sekeluarga tidak lama tinggal di Pekanbaru, karena ayahku ditugaskan kembali bekerja di Jambi.

Kesalahan lain mengenai kalimat ambigu juga terdapat pada teks biografi siswa dalam contoh kalimat berikut.

2) Mamalah yang paling berjasa dan mamalah yang sangat mengerti gimana dan bagaimana anaknya.

Kalimat (2) merupakan kalimat ambigu karena memiliki makna ganda. Penggunaan kata gimana dan kata bagaimana hanya digunakan salah satu karena rujukan kata tersebut memiliki makna yang sama sehingga kalimat tersebut menjadi kalimat efektif. Bentuk yang benar dari kalimat (2) tersebut adalah mama sosok yang berjasa dan memahami bagaimana kondisi anaknya.

Selain itu kesalahan pada kalimat ambigu juga terdapat pada teks biografi siswa seperti yang dipaparkan di bawah ini.

3) Beliau menamatkan sekolah dasar di SDN 44 Alang Lawas.

Kalimat (3) merupakan kalimat ambigu karena memiliki makna ganda. Penggunaan kata menamatkan memiliki dua makna, yaitu beliau yang tamat dari sekolah dasar di SDN 44 Alang Lawas atau sekolah dasar SDN 44 Alang Lawas yang tamat dari beliau. Seharusnya penulisan kalimat (3) yang benar adalah beliau tamat dari sekolah dasar di SDN 44 Alang Lawas.

Jadi, penulisan kalimat ambigu sering terjadi ketika siswa menuliskan sebuah kalimat dengan kata-kata yang kurang tepat. Hal ini disebabkan masih kurangnya pengetahuan siswa tentang kalimat ambigu.

\section{Diksi yang Tidak Tepat dalam Membentuk Kalimat}

Diksi adalah pilihan kata yang tepat dan selaras untuk menggunakan gagasan sehingga diperoleh efek tertentu. Pemilihan kata-kata yang layak atau pantas penting sekali dalam semua bentuk komunikasi, terutama dalam bahasa tulis yang harus membawakan ide atau gagasan dan sikap tanpa peragaan, ekspresi, intonasi, atau isyarat berupa gerakan tubuh (Santoso, 2007).

Pilihan kata merupakan suatu unsur yang sangat penting dalam memilih kata 


\section{DEIKSIS - JURNAL PENDIDIKAN BAHASA DAN SASTRA INDONESIA}

yang tepat untuk menyatakan suatu maksud. Menurut Kridalaksana (dalam Puspitasari, 2016) diksi adalah pilihan kata dan kejelasan lafal untuk menggambarkan efek tertentu dalam berbicara di depan umum atau dalam karang mengarang. Dalam menyusun kalimat kita harus memilih kata yang tepat sesuai dengan maknanya.

Pada tugas siswa terdapat pemilihan diksi yang tidak tepat dalam membentuk kalimat. Beberapa kesalahan pemilihan diksi tersebut dapat dilihat pada kalimat berikut.

4) Ia kembali melamar kerja menjadi laboran di labor mikropak dan berhenti lagi karna labor ditutup.

5) Mama berjurusan PGLD S1.

6) Mama adalah seorang motivator yang sangat berarti dalam hidupku dan paling $\mathrm{ku}$ junjung dan $\mathrm{ku}$ hormati.

7) Beliau anak nomor enam dari sepuluh bersaudara.

Kalimat-kalimat di atas termasuk karakteristik kesalahan diksi yang tidak tepat dalam membentuk kalimat. Dalam kalimat (4) pilihan kata labor tidak tepat sehingga tidak sinkron dengan kata selanjutnya. Sebelum kata labor terdapat kata laboran. Kata laboran telah menunjukkan arti orang ahli yang bekerja di laboratorium sehingga kata labor tidak cocok digunakan. Bentuk benar dari kalimat (4) tersebut adalah ia kembali melamar pekerjaan menjadi laboran di Mikropark dan berhenti bekerja karena tempat tersebut ditutup.

Kalimat (5) pilihan kata berjurusan kurang efektif, karena kata berjurusan memiliki kata dasar jurusan. Kata dasar jurusan tidak mengalami proses afiksasi dengan penambahan ber-,-an. Bentuk benar dari kalimat (5) tersebut adalah mama menyelesaikan studi S-1 dengan jurusan PGLD.

Kalimat (6) pilihan kata junjung tidak tepat karena kata junjung digunakan untuk kata kerja yang memiliki makna mengangkat sesuatu di atas kepala. Seharusnya kalimat (6) menggunakan kata sanjung. Selain itu pada kalimat (6) menggunakan kata hubung dan terlalu banyak, seharusnya kata dan yang kedua diganti menjadi. Bentuk benar dari kalimat (6) mama adalah seorang motivator yang sangat berarti dalam hidupku dan paling ku sanjung serta kuhormati.

Kalimat (7) pilihan kata nomor kurang tepat, karena kata nomor digunakan untuk mengurutkan angka. Seharusnya digunakan kata ke-. Bentuk benar kalimat tersebut adalah beliau anak keenam dari sepuluh bersaudara.

Jadi, penggunaan diksi yang tidak tepat dalam membentuk kalimat masih banyak didapat dalam tugas siswa. Masih kurangnya pengetahuan siswa dalam memilih kata yang tepat dalam membentuk kalimat.

\section{Logika Kalimat}

Logika kalimat adalah pengetahuan tentang kaidah berpikir yang masuk akal dalam sebuah kalimat. Ada beberapa kesalahan yang terdapat dalam tugas siswa yang berkaitan dengan logika kalimat. Kesalahan tersebut dapat dilihat pada kalimat berikut. 


\section{DEIKSIS - JURNAL PENDIDIKAN BAHASA DAN SASTRA INDONESIA}

8) Ia adalah anak ketiga dari lima bersaudara, buah dari pasangan Baharudin dan Rosni.

Kalimat (8) tidak logis karena kata buah kurang tepat yang berarti bagian tumbuhan yang berasal dari bunga atau putik. Kata tersebut menjadi logis dan dalam kalimat jika diganti menjadi buah hati. Maka, bentuk benar kalimat tersebut adalah (8) Ia adalah anak ketiga dari lima bersaudara, buah hati dari pasangan Baharudin dan Rosni.

Selain itu, kesalahan logika kalimat pada teks biografi karangan siswa terdapat pada kalimat berikut.

(9) Ibuku bernama Nova Leni, ia lahir pada tanggal 15 November 1976 dari seorang ayah yang bernama Ahmadin dan seorang ibu yang bernama Elira.

Pada kalimat (9) tidak logis karena Nova Leni lahir dari seorang ayah. Seorang anak tidak lahir dari seorang ayah, melainkan dari seorang ibu. Jadi, kalimat (9) yang benar adalah ibuku bernama Nova Leni, ia lahir pada tanggal 15 November 1976 dari seorang ibu yang bernama Elira dan suaminya bernama Ahmadin.

Kesalahan kalimat tentang logika kalimat masih terlihat dalam teks biografi siswa, keselahan tersebut dipaparkan sebagai berikut.

(10) Ia mulai menginjak bangku pendidikan saat ia berusia 6 tahun.
Pada kalimat (10) tidak logis karena kata menginjak kurang tepat yang berarti meletakkan kaki. Seharusnya, bentuk kalimat (10) yang benar adalah ia mulai bersekolah saat berusia 6 tahun.

Jadi, dalam logika kalimat tugas siswa ini masih banyak kesalahan dan masih menggunakan kalimat-kalimat yang tidak masuk akal.

Penelitian mengenai kesalahan berbahasa dalam bidang sintaksis dilakukan untuk mengetahui bagaimana tingkat kemahiran berbahasa siswa SMA Negeri 7 Padang. Pada pelajaran bahasa Indonesia, siswa dituntut untuk mengerti tentang sebuah teks dan mampu menghasilkan atau memproduksi teks itu sendiri. Penelitian ini dapat dijadikan sebagai pedoman evaluasi sehingga guru dan siswa mampu memperbaiki kesalahan-kesalahan saat mempelajari kebahasaan khususnya pada bidang sintaksis. Hasil yang dicapai dalam penelitian ini adalah menambah wawasan dan keterampilan berbahasa khususnya pada bidang sintaksis saat menulis sebuah kalimat, paragraf, atau teks.

\section{SIMPULAN}

Berdasarkan hasil analisis data dan pembahasan yang telah dijelaskan mengenai analisis kesalahan berbahasa bidang sintaksis dalam teks biografi siswa kelas $\mathrm{X}$ SMA Negeri 7 Padang dapat disimpulkan beberapa kesalahan berbahasa bidang sintaksis yang terdapat dalam teks biografi siswa kelas X SMA Negeri 7 Padang. Kesalahan tersebut meliputi tiga aspek yaitu, pertama kalimat ambigu, kedua diksi yang 


\section{DEIKSIS - JURNAL PENDIDIKAN BAHASA DAN SASTRA INDONESIA}

tidak tepat dalam membentuk kalimat, dan ketiga logika kalimat.

Dari ketiga kesalahan tersebut, kesalahan yang paling banyak terjadi di antara tugas siswa dalam teks biografi kelas $\mathrm{X}$ SMA Negeri 7 Padang adalah pada kesalahan diksi yang tidak tepat dalam membentuk kalimat. Siswa masih banyak menggunakan kata-kata yang tidak tepat untuk menyatakan maksud yang ingin ditulisnya. Hal ini disebabkan kurangnya pengetahuan siswa dalam bidang sintaksis khususnya kategori diksi.

Berdasarkan penelitian yang telah dilakukan, dapat disarankan hal-hal sebagai berikut. Pertama, guru di SMA Negeri 7 Padang diharapkan banyak memberikan latihan menentukan kalimat agar siswa bisa menggunakan kalimat yang efektif dan tidak menggunakan kalimat ambigu. Kedua, guru di SMA Negeri 7 Padang diharapkan memperhatikan dan memberikan latihan dalam menulis kalimat yang tepat sesuai dengan pemilihan diksi yang digunakan. Ketiga, guru di SMA Negeri 7 Padang diharapkan memperhatikan dan memberikan latihan menulis kalimat agar siswa menggunakan kaimat sesuai dengan logika kalimat.

\section{DAFTAR PUSTAKA}

Alwi, H., dkk. (2010). "Tata Bahasa Baku: Bahasa Indonesia". Jakarta: Balai Pustaka.

Atmazaki. (2006). "Kiat-kiat Mengarang dan Menyunting" Padang: Cipta Budaya.
Chaer, A. (2009). "Struktur Bahasa Indonesia (Pendekatan Proses)”. Jakarta: Rineka Cipta.

Dunkin, M.J. dan Biddle, B.J. (1974).The Study of Teaching. New York: Holt Rinehart and Winston.

Kusmaningsih, D., dkk. (2013). "Terampil Berbahasa Indonesia". Yoyakarta: Penerbit Andi.

Moleong, L., J. (2010). "Metode Penelitian Kualitatif'. Bandung: Remaja Rasdakarya.

Nurtiah, S., Ngusman., Emidar. (2016).

"Kesalahan Kalimat dalam Teks

Eksposisi Siswa Kelas VII SMP

Negeri 12 Padang”. Jurnal

Komposisi Vol. 5 (2), 446-455.

Puspita, D., F. (2016). "Analisis

Kesalahan Bidang Sintaksis Pada

Buku Teks Pelajaran Bahasa dan

Sastra Indonesia untuk SMA dan MA Kelas X”. Naskah Publikasi Sarjana Pendidikan dan Program Studi Pendidikan Bahasa Indonesia. Surakarta: Universitas

Muhammadiyah Surakarta.

Santoso, T. (2007). "Diksi dan Pola Sintaksis dalam Pepatah Aceh". Jurnal Humaniora Vol. 19(3), 309316.

Septiana, A.N., Sumarwati., Suyitno. (2015). “Analisis Kesalahan Struktur Teks dan Pemakaian Bahasa Indonesia pada Teks Biografi Karya Siswa SMP”. BASASTRA Jurnal Penelitian Bahasa Sastra Indonesia, dan Pengajarannya Vol. 3 (3), 1-13. Setiawan, A. D. (2016). "Analisis Kesalahan Sintaksis Bahasa 


\section{DEIKSIS - JURNAL PENDIDIKAN BAHASA DAN SASTRA INDONESIA}

Indonesia dalam Karangan Deskripsi

Siswa Kelas VI SDN Kanigoro 02

Kecamatan Pagelaran yang

Berbahasa Ibu Bahasa Madura".

Journal Pancaran Vol. 5 (3), 26-36.

Surjaweni, V., Wiratno. (2014). "Metode

Penelitian Lengkap Praktis dan

Mudah Dipahami”. Yogyakarta:

Pusatakabarupres 